\title{
A smaller post-procedural hemoglobin fall in patients with preexisting anemia undergoing atrial fibrillation ablation with a single skipped dose of direct oral anticoagulants: Another anemia paradox
}

\author{
Akinori Sairaku ${ }^{1}$, Nobuyuki Morishima ${ }^{1}$, Hiroki Kinoshita ${ }^{1}$, Michitaka Amioka ${ }^{1}$, Junji \\ Maeda $^{1}$, Yoshikazu Watanabe ${ }^{2}$, and Yukiko Nakano ${ }^{3}$ \\ ${ }^{1}$ Onomichi General Hospital \\ ${ }^{2}$ Hiroshima General Hospital \\ ${ }^{3}$ Hiroshima University
}

July 27, 2020

\begin{abstract}
Background: There is a concern about worsening of anemia after atrial fibrillation (AF) ablation in anemic patients. We aimed to clarify whether or not patients with anemia who are on an oral anticoagulant therapy are more likely to lose blood after AF ablation. Methods: We studied AF patients in 3 cardiovascular centers who skipped a single dose of direct oral anticoagulants prior to the ablation, and compared the drop in the hemoglobin level 24 hours after the procedure and bleeding complications between the patients with and without preexisting anemia. Results: We identified $183(15.7 \%)$ patients with anemia at baseline out of 1163 patients. The reduction in the hemoglobin level $(-0.39 \pm 0.71$ vs. $-0.93 \pm 0.9 \mathrm{~g} / \mathrm{dL} ; \mathrm{P}<0.001)$ was smaller in the anemic than non-anemic patients. A fall in the hemoglobin level of [?]2 $\mathrm{g} / \mathrm{dL}$ was less common in anemic patients (1.6\% vs. $11.3 \% ; \mathrm{P}<0.001$ ). A female gender (odds ratio $[\mathrm{OR}] 1.62$, confidence interval $[\mathrm{CI}] 1.07-2.45 ; \mathrm{P}=0.02$ ), persistent or longstanding persistent versus paroxysmal $\mathrm{AF}$ (OR 1.67, CI 1.13-2.49; $\mathrm{P}=0.01$ ), ORBIT score [?]3 (OR 3.5, CI 1.34-8.94; $\mathrm{P}=0.01$ ), and preexisting anemia (OR 0.02, CI 0.004-0.14; $\mathrm{P}<0.001$ ) were independently associated with the fall in the hemoglobin level of $[?] 2 \mathrm{~g} / \mathrm{dL}$. No difference was noted in the rate of major bleeding complications (1.6\% vs. 1.2\%; $\mathrm{P}=0.72)$. Conclusions: Paradoxically, patients with preexisting anemia may be less likely to lose blood following AF ablation.
\end{abstract}

\section{Introduction}

Catheter ablation of atrial fibrillation (AF) has become the first-line treatment for a selected population [1]. Oral anticoagulation remains an essential treatment for patients with AF regardless of whether or not they undergo the ablation. Anemia is often encountered in subjects with AF who are on anticoagulant treatment with direct oral anticoagulants (DOACs) in clinical practice [2]. To date, preexisting anemia is not considered a predictor of major hemorrhagic complications during the periablation period [3]. Still, there is concern about further blood loss due to the ablation procedure in anemic patients since it requires an insertion of several large-diameter vascular sheaths and intense intraprocedural anticoagulation with heparin [3]. We then in the present study sought to investigate whether there was a difference in blood loss following AF ablation between patients with and without preexisting anemia.

\section{Methods}

Patients 
This is a retrospective and multicenter study of the impact of preexisting anemia on the post-procedural hemoglobin drop following AF ablation. The databases of AF ablation were reviewed in Onomichi General Hospital, Hiroshima General Hospital, and Hiroshima University Hospital. The data from January 2016 to December 2019 were collected. The study protocol was approved by the research committee of each institution. Consecutive AF patients with or without preexisting anemia were considered eligible for inclusion if they underwent a radiofrequency-based pulmonary vein isolation for the first time, and a single dose of rivaroxaban, apixaban, edoxaban, or dabigatran had been skipped prior to their ablation procedures. Patients were excluded if they were prescribed with inappropriate DOAC dose regimens, underwent their ablation procedures in the afternoon, or adjunctive ablation procedures such as cavotricuspid isthmus ablation, linear lesions, superior vena cava isolation, or ablation of non-pulmonary vein triggers. For risk stratification of thromboembolisms and bleedings, the $\mathrm{CHA}_{2} \mathrm{DS}_{2}$-VASc [4] and ORBID [5] scores were calculated in all patients.

\section{Definition of anemia}

Blood samples were collected the day before and 24 hours after the ablation in each patient. A complete blood cell count, coagulation markers, and serum chemistry were measured.

Anemia was diagnosed when the hemoglobin level was $<13 \mathrm{~g} / \mathrm{dL}$ in men and $<12 \mathrm{~g} / \mathrm{dL}$ in women [6]. Causes of anemia were based on the reports from referring physicians, if any.

\section{Oral anticoagulation regimens}

The following 4 DOACs had been prescribed at least 4 weeks before the ablation: rivaroxaban, apixaban, edoxaban, and dabigatran. The choice of the DOAC was left to the discretion of each referring physician. On the basis of the current guidelines on the use of DOACs [7] or landmark trials [8-10], the standard doses of apixaban, edoxaban, and dabigatran were determined as $5 \mathrm{mg} \mathrm{BID}, 60 \mathrm{mg}$ OD, and $150 \mathrm{mg}$ BID, respectively. A landmark trial [11] and the guidelines [7] recommend a $20 \mathrm{mg}$ OD as a standard dose for rivaroxaban. However, based on the J-ROCKET AF trial [12] that included only Japanese patients, its Japan-specific standard dose of $15 \mathrm{mg}$ OD predominated in Japan. The rivaroxaban dose was reduced to 10 $\mathrm{mg}$ OD if patients had a creatinine clearance of [?]50 ml/min [12]. For apixaban, the reduced dose of $2.5 \mathrm{mg}$ BID was given if patients had 2 of the following 3 factors: age [?] 80 years, creatinine [?]1.5 $\mathrm{mg} / \mathrm{dL}$, and body weight [?]60 $\mathrm{kg}[7,8]$. Patients received a lower edoxaban dose of $30 \mathrm{mg}$ OD if they had a creatinine clearance of [?]50 ml/min or body weight [?]60 $\mathrm{kg}[7,9]$. To date, there is no pre-specified dose-reduction criteria for dabigatran [7]. In the present study, we considered it an appropriate dose reduction if dabigatran $110 \mathrm{mg}$ BID was prescribed in the patients who were older than 80 years or had a history of massive bleeding [13]. Patients with OD or BID dosing regimens were instructed to take their total or morning dose, respectively, with breakfast. Patients with BID dosing regimens were encouraged to take the evening dose at dinner. On the procedural day, the normal daily dose was not taken until the post-procedural evening in patients with OD dose regimens. The morning dose on the procedural day was skipped, and the evening dose was taken on the post-procedural evening as usual in patients with BID dosing regimens. In the patients prescribed with any antiplatelets, they were withheld for at least 7 days before the procedure. A bridging therapy with heparin was not applied.

\section{Anticoagulation during ablation}

Intraablation anticoagulation was performed on the basis of the current guidelines [3]. An initial heparin bolus of 120 units/ $\mathrm{kg}$ was intravenously administered immediately after the sheath insertion, followed by its continuous infusion of 30-50 units $/ \mathrm{kg} / \mathrm{h}$. Additional heparin boluses were repeated to achieve an activated clotting time (ACT) of 300-350 sec, if necessary. The ACT was checked at 15-minute intervals until its target value was achieved, and then at 30-minute intervals for the duration of the procedure. A 20-40 mg dose of protamine was routinely infused to reverse the heparin at the end of the procedure.

\section{Ablation procedure}

The ablation procedures were started in the morning. The details of the double Lasso catheter-guided 
extensive encircling pulmonary vein antrum isolation performed in this study have been described previously [14]. In brief, 2 decapolar circular catheters were positioned within the ipsilateral superior and inferior pulmonary veins. Circumferential ablation lines were created around the left- and right-sided ipsilateral pulmonary veins with the use of a $3.5 \mathrm{~mm}$-tip irrigated catheter (Thermocool SmartTouch ${ }^{\circledR}$, Biosense Webster, Diamond Bar, CA, USA). Radiofrequency energy was delivered with a maximum power of 30 Watt. Real-time contact force data were used to guide the ablation procedures, with a target force of 10-15 g. The goal of the procedure was to achieve both pulmonary vein entrance and exit block [3].

\section{Endpoints}

The subcommittee on control of anticoagulation of the Scientific and Standardization committee of the International Society on Thrombosis and Haemostasis [15] recommends that bleeding causing a fall in the hemoglobin level of $2 \mathrm{~g} / \mathrm{dL}$ or more meets the criteria for major bleeding. Based on this recommendation, a fall in the hemoglobin level from baseline of [?]2 $\mathrm{g} / \mathrm{dL} 24$ hours after the ablation was determined as the primary endpoint, regardless of whether or not any overt bleeding was seen. The secondary endpoints included major or minor bleeding complications. Major bleeding complication was defined as the occurrence of cardiac tamponade, hematoma requiring intervention, hemothorax, or retroperitoneal bleeding. Minor bleeding complications were defined as hematoma or any bleeding that did not require any intervention or a prolonged hospital stay [16].

\section{Statistical analysis}

The continuous variables are summarized as the means+-SD, and categorical variables as proportions. The differences between the patients with and without preexisting anemia were examined with the use of Pearson Chi-Square test or Fisher's exact test for categorical variables, or Student t-test or Mann-Whitney U test for continuous variables. Univariate and multivariate logistic regression models were used to determine the factors independently associated with the primary endpoint. Likely parameters were included as explanatory variables in the univariate models. For some continuous variables included in the models, the cut-off points were determined according to their upper or lower normal limits, otherwise, the medians. Variables with a $\mathrm{P}$ value of $<0.1$ in the univariate analyses were further included in the multivariate models. All statistical analyses were performed with the use of JMP software version 13.0 (SAS Institute, Cary, NC, USA). A P value of $<0.05$ was considered significant.

\section{Results}

\section{Patients}

A total of 1639 patients were considered eligible. Among them, 476 patients met the exclusion criteria; 21 with an inadequate dose reduction of DOACs, 285 with afternoon procedures, 201 with adjunctive ablation procedures including 78 cavotricuspid isthmus ablations, 69 linear lesions, 32 superior vena cava isolations, and 42 non-pulmonary vein trigger ablations. We thus finally studied 1163 patients. We found $183(15.7 \%)$ patients with preexisting anemia, whose hemoglobin levels were $12+-0.9 \mathrm{~g} / \mathrm{dL}$ in males and $11.2+-0.6 \mathrm{~g} / \mathrm{dL}$ in females. No patients with severe anemia with a hemoglobin level of $<9.0 \mathrm{~g} / \mathrm{dL}$ were noted. Patients with preexisting anemia were older, smaller, and more likely to be female than those without. The anemic patients had a more decreased estimated glomerular filtration ratio, more increased D-dimer level, and greater $\mathrm{CHA}_{2} \mathrm{DS}_{2}$-VASc and ORBIT scores. The anemic patients were more likely to be prescribed with apixaban and a reduced dose of DOACs, and were less likely to be given dabigatran (Table 1). Although the etiology of the preexisting anemia had not been investigated in the majority of anemic patients at the referring clinics, renal insufficiency and iron deficiency were the dominant causes (Table 2).

\section{Intraprocedural data}

The average and maximum ACT were shorter in patients with preexisting anemia than in those without, and there was a trend toward a longer time from the initial heparin injection to the first achievement of the

target ACT in the anemic patients. No difference was noted between the patient groups in the procedural duration and procedural heparin requirement (Table 3). 


\section{Fall in the hemoglobin level}

The reduction in the hemoglobin level $(-0.39+-0.71$ vs. $-0.93+-0.9 \mathrm{~g} / \mathrm{dL} ; \mathrm{P}<0.001)$ and its $\%$ reduction $(-3.3+-6.1$ vs. $-6.3+-6.1 \% ; \mathrm{P}<0.001)$ were smaller in the patients with preexisting anemia than in those without (Figure 1). A fall in the hemoglobin level of [?]2 $\mathrm{g} / \mathrm{dL}$ was less common in anemic patients (Figure 2). A female gender, persistent or longstanding persistent versus paroxysmal AF, and ORBIT score [?]3 were found to be independently and positively associated with, and preexisting anemia was negatively associated with, the fall in the hemoglobin level of [?]2 $\mathrm{g} / \mathrm{dL}$ (Table 4).

\section{Complications}

We encountered $3(1.6 \%)$ and $12(1.2 \%)$ major bleeding complications in patients with and without preexisting anemia, respectively, and found no difference in the frequency of major and minor hemorrhagic complications between the groups (Table 5). Ischemic stroke was noted in 2 patients without preexisting anemia. No other serious complications including death were encountered in the entire study subjects.

\section{Discussion}

\section{Major findings}

The major findings of the present study were twofold. (1) A reduction in the hemoglobin level following AF ablation was rather smaller in the anemic patients, and preexisting anemia was an independent negative predictor of a fall in the hemoglobin level of [?]2 g/dL. (2) Preexisting anemia did not increase the procedural bleeding complications.

\section{New anemia paradox}

Anemia is known as one of the risk factors of major bleeding in subjects treated with antithrombotic agents [5,17-19]. Our findings thus seem to be contradictory. Would the present study be "heretical"? There are 2 studies with a large number of participants that reported similar findings to ours [19,20], where subjects with anemia at baseline had a smaller hemoglobin drop following coronary or peripheral vascular interventions compared to those without. The authors did not provide any comments on this paradoxical finding, though. What is the mechanism? It is well-known that thalassemia, sickle cell disease, and other hemolytic anemias can cause thromboembolic events [21]. The same can be said for more common types of anemia. For instance, anemia was found to be an independent predictor of myocardial infarction and stroke in the RELY trial substudy [18]. A tight link between iron deficiency anemia and venous thrombosis or ischemic stroke has been repeatedly reported in adults and children [22-24]. The proposed mechanisms behind the hypercoagulability in anemia include (1) reactive thrombocytosis [23,25,26], (2) erythropoietin-mediated platelet hypersensitivity [26], (3) endothelial damage caused by increased blood flow to compensate for an oxygen deficiency [25.26], or (4) increased blood viscosity due to a morphological change in the erythrocytes $[25,26]$. Let us look at our data regarding blood tests and intraprocedural anticoagulation. The D-dimer level at baseline was higher in the anemic patients. Their procedural ACT was lower, and they had a tendency to require a longer time to achieve the target ACT, despite a similar amount of heparin given compared to non-anemic patients. These findings may indicate the potential increased coagulability in anemic subjects, and it might have been rather advantageous for reducing the blood loss.

Again, there is a consensus that anemia increases bleeding complications in antithrombotic therapy. Why did not this anemia's aspect come to the fore in the present study? In general, anemia itself is not the cause but the effect of bleeding as long as no anticoagulants are on board. Accordingly, anemia must not increase the risk of bleeding once the anticoagulants are withdrawn. In our series, patients skipped a single dose of their DAOC prior to the ablation, and thus, their remaining anticoagulant effect was probably vanishingly small during the procedure, thanks to their short half-lives [7]. Therefore, the bleeding risk in anemic patients might have been the same as that in the non-anemic patients during the procedure. On the other hand, the potential hypercoagulable state caused by anemia must have remained, and consequently the anemia's hypercoagulable aspect may have come to the front, instead. An alternative likely explanation is that the operators might have been more careful not to lose blood in the patients with preexisting anemia, which 
perhaps may not appear in any data. Consequently, this operator's effort might have done more than just cancel out the higher bleeding risk of anemic patients.

\section{Clinical implications}

Importantly, our findings never suggest any superiority of anemic over non-anemic subjects in reducing the procedural blood loss or bleeding complications. However, the findings might offer encouragement to operators who hesitate to ablate AF patients with mild anemia.

\section{Limitations}

We only studied patients with rather mild anemia. Accordingly, whether or not our findings are the case with severe anemia is unknown. Once again, the etiology of anemia was not investigated in the majority of anemic patients. Finally, the present study is a retrospective one.

\section{Conflict of interest}

None declared.

\section{References}

1. January CT, Wann LS, Alpert JS, Calkins H, Cigarroa JE, Cleveland JC Jr, Conti JB, Ellinor PT, Ezekowitz MD, Field ME, Murray KT, Sacco RL, Stevenson WG, Tchou PJ, Tracy CM, Yancy CW; ACC/AHA Task Force Members. 2014 AHA/ACC/HRS Guideline for the Management of Patients With Atrial Fibrillation: Executive Summary: A Report of the American College of Cardiology/American Heart Association Task Force on Practice Guidelines and the Heart Rhythm Society. Circulation. 2014;130:2071-104.

2. Stauder R, Valent P, Theurl I. Anemia at older age: etiologies, clinical implications, and management. Blood. 2018;131:505-514.

3. Calkins H, Hindricks G, Cappato R, Kim YH, Saad EB, Aguinaga L, Akar JG, Badhwar V, Brugada J, Camm J, Chen PS, Chen SA, Chung MK, Cosedis Nielsen J, Curtis AB, Davies DW, Day JD, d'Avila A, Natasja de Groot NMS, Di Biase L, Duytschaever M, Edgerton JR, Ellenbogen KA, Ellinor PT, Ernst S, Fenelon G, Gerstenfeld EP, Haines DE, Haissaguerre M, Helm RH, Hylek E, Jackman WM, Jalife J, Kalman JM, Kautzner J, Kottkamp H, Kuck KH, Kumagai K, Lee R, Lewalter T, Lindsay BD, Macle L, Mansour M, Marchlinski FE, Michaud GF, Nakagawa H, Natale A, Nattel S, Okumura K, Packer D, Pokushalov E, Reynolds MR, Sanders P, Scanavacca M, Schilling R, Tondo C, Tsao HM, Verma A, Wilber DJ, Yamane T; Document Reviewers: 2017 HRS/EHRA/ECAS/APHRS/SOLAECE expert consensus statement on catheter and surgical ablation of atrial fibrillation. Europace. 2018;20:e1-e160.

4. Lip GY, Nieuwlaat R, Pisters R, Lane DA, Crijns HJ. Refining clinical risk stratification for predicting stroke and thromboembolism in atrial fibrillation using a novel risk factor-based approach: the euro heart survey on atrial fibrillation. Chest. 2010;137:263-72.

5. O'Brien EC, Simon DN, Thomas LE, Hylek EM, Gersh BJ, Ansell JE, Kowey PR, Mahaffey KW, Chang P, Fonarow GC, Pencina MJ, Piccini JP, Peterson ED. The ORBIT bleeding score: a simple bedside score to assess bleeding risk in atrial fibrillation. Eur Heart J. 2015;36:3258-64.

6. Blanc B, Finch CA, Hallberg L, et al. Nutritional anaemias. Report of a WHO scientific group. World Health Organ Tech Rep Ser. 1968;405:5-37.

7. Steffel J, Verhamme P, Potpara TS, Albaladejo P, Antz M, Desteghe L, Haeusler KG, Oldgren J, Reinecke H, Roldan-Schilling V, Rowell N, Sinnaeve P, Collins R, Camm AJ, Heidbuchel H; ESC Scientific Document Group. The 2018 European Heart Rhythm Association Practical Guide on the use of non-vitamin $\mathrm{K}$ antagonist oral anticoagulants in patients with atrial fibrillation. Eur Heart J. 2018;39:1330-1393.

8. Granger CB, Alexander JH, McMurray JJ, Lopes RD, Hylek EM, Hanna M, Al-Khalidi HR, Ansell J, Atar D, Avezum A, Bahit MC, Diaz R, Easton JD, Ezekowitz JA, Flaker G, Garcia D, Geraldes M, Gersh BJ, Golitsyn S, Goto S, Hermosillo AG, Hohnloser SH, Horowitz J, Mohan P, Jansky P, Lewis BS, Lopez-Sendon JL, Pais P, Parkhomenko A, Verheugt FW, Zhu J, Wallentin L; ARISTOTLE 
Committees and Investigators. Apixaban versus warfarin in patients with atrial fibrillation. N Engl J Med. 2011;365:981-92.

9. Giugliano RP, Ruff CT, Braunwald E, Murphy SA, Wiviott SD, Halperin JL, Waldo AL, Ezekowitz MD, Weitz JI, Špinar J, Ruzyllo W, Ruda M, Koretsune Y, Betcher J, Shi M, Grip LT, Patel SP, Patel I, Hanyok JJ, Mercuri M, Antman EM; ENGAGE AF-TIMI 48 Investigators. Edoxaban versus warfarin in patients with atrial fibrillation. N Engl J Med. 2013;369:2093-104.

10. Connolly SJ, Ezekowitz MD, Yusuf S, Eikelboom J, Oldgren J, Parekh A, Pogue J, Reilly PA, Themeles E, Varrone J, Wang S, Alings M, Xavier D, Zhu J, Diaz R, Lewis BS, Darius H, Diener HC, Joyner CD, Wallentin L; RE-LY Steering Committee and Investigators. Dabigatran versus warfarin in patients with atrial fibrillation. N Engl J Med. 2009;361:1139-51.

11. Patel MR, Mahaffey KW, Garg J, Pan G, Singer DE, Hacke W, Breithardt G, Halperin JL, Hankey GJ, Piccini JP, Becker RC, Nessel CC, Paolini JF, Berkowitz SD, Fox KA, Califf RM; ROCKET AF Investigators. Rivaroxaban versus warfarin in nonvalvular atrial fibrillation. $\mathrm{N}$ Engl $\mathrm{J}$ Med. 2011;365:883-91.

12. Hori M, Matsumoto M, Tanahashi N, Momomura S, Uchiyama S, Goto S, Izumi T, Koretsune $\mathrm{Y}$, Kajikawa M, Kato M, Ueda H, Iwamoto K, Tajiri M; J-ROCKET AF study investigators. Safety and efficacy of adjusted dose of rivaroxaban in Japanese patients with non-valvular atrial fibrillation: subanalysis of J-ROCKET AF for patients with moderate renal impairment. Circ J. 2013;77:632-8.

13. Farmakis D, Davlouros P, Giamouzis G, Giannakoulas G, Pipilis A, Tsivgoulis G, Parissis J. Direct Oral Anticoagulants in Nonvalvular Atrial Fibrillation: Practical Considerations on the Choice of Agent and Dosing. Cardiology. 2018;140:126-132.

14. Watanabe R, Sairaku A, Yoshida Y, Nanasato M, Kamiya H, Suzuki H, Ogura Y, Aoyama Y, Maeda M, Ando M, Eguchi S, Inden Y, Kihara Y, Murohara T. Head-to-head comparison of acute and chronic pulmonary vein stenosis for cryoballoon versus radiofrequency ablation. Pacing Clin Electrophysiol. 2018;41:376-382.

15. Schulman S, Kearon C; Subcommittee on Control of Anticoagulation of the Scientific and Standardization Committee of the International Society on Thrombosis and Haemostasis. Definition of Major Bleeding in Clinical Investigations of Antihemostatic Medicinal Products in Non-Surgical Patients. J Thromb Haemost. 2005;3:692-4

16. Di Biase L, Burkhardt JD, Santangeli P, Mohanty P, Sanchez JE, Horton R, Gallinghouse GJ, Themistoclakis S, Rossillo A, Lakkireddy D, Reddy M, Hao S, Hongo R, Beheiry S, Zagrodzky J, Rong B, Mohanty S, Elayi CS, Forleo G, Pelargonio G, Narducci ML, Dello Russo A, Casella M, Fassini G, Tondo C, Schweikert RA, Natale A. Periprocedural stroke and bleeding complications in patients undergoing catheter ablation of atrial fibrillation with different anticoagulation management: results from the Role of Coumadin in Preventing Thromboembolism in Atrial Fibrillation (AF) Patients Undergoing Catheter Ablation (COMPARE) randomized trial. Circulation. 2014;129:2638-44.

17. Shaun G Goodman, Daniel M Wojdyla, Jonathan P Piccini, Harvey D White, John F Paolini, Christopher C Nessel, Scott D Berkowitz, Kenneth W Mahaffey, Manesh R Patel, Matthew W Sherwood, Richard C Becker, Jonathan L Halperin, Werner Hacke, Daniel E Singer, Graeme J Hankey, Gunter Breithardt, Keith A A Fox, Robert M Califf, ROCKET AF Investigators. Factors Associated With Major Bleeding Events: Insights From the ROCKET AF Trial (Rivaroxaban Once-Daily Oral Direct Factor Xa Inhibition Compared With Vitamin K Antagonism for Prevention of Stroke and Embolism Trial in Atrial Fibrillation). J Am Coll Cardiol. 2014;63:891-900.

18. Westenbrink BD, Alings M, Connolly SJ, Eikelboom J, Ezekowitz MD, Oldgren J, Yang S, Pongue J, Yusuf S, Wallentin L, van Gilst WH. Anemia Predicts Thromboembolic Events, Bleeding Complications and Mortality in Patients With Atrial Fibrillation: Insights From the RE-LY Trial. J Thromb Haemost. 2015;13:699-707.

19. Brener SJ, Mehran R, Dangas GD, Ohman EM, Witzenbichler B, Zhang Y, Parvataneni R, Stone GW. Relation of Baseline Hemoglobin Levels and Adverse Events in Patients With Acute Coronary Syndromes (from the Acute Catheterization and Urgent Intervention Triage strategY and Harmonizing Outcomes with RevasculariZatiON and Stents in Acute Myocardial Infarction Trials). Am J Cardiol. 
2017;119:1710-1716.

20. Jaffery Z, White CJ, Collins TJ, Grise MA, Jenkins JS, McMullan PW, Patel RA, Reilly JP, Thornton SN, Ramee SR. Factors related to a clinically silent peri-procedural drop in hemoglobin with coronary and peripheral vascular interventions. Vasc Med. 2011;16:354-9.

21. Byrnes JR, Wolberg AS. Red blood cells in thrombosis. Blood. 2017;130:1795-1799.

22. Maguire JL, deVeber G, Parkin PC. Association between iron-deficiency anemia and stroke in young children. Pediatrics. 2007;120:1053-7.

23. Stolz E, Valdueza JM, Grebe M, Schlachetzki F, Schmitt E, Madlener K, Rahimi A, Kempkes-Matthes B, Blaes F, Gerriets T, Kaps M. Anemia as a risk factor for cerebral venous thrombosis? An old hypothesis revisited. Results of a prospective study. J Neurol. 2007;254:729-34.

24. Hung SH, Lin HC, Chung SD. Association between venous thromboembolism and iron-deficiency anemia: a population-based study. Blood Coagul Fibrinolysis. 2015;26:368-72.

25. Franchini M, Targher G, Montagnana M, Lippi G. Iron and thrombosis. Ann Hematol. 2008;87:167-73.

26. Özdemir ZC, Düzenli Kar Y, Gündüz E, Turhan AB, Bör Ö. Evaluation of hypercoagulability with rotational thromboelastometry in children with iron deficiency anemia. Hematology. 2018;23:664-668.

\section{Figure legends}

Figure 1.

Change (A) and percent change (B) in the hemoglobin level before and 24 hours after the atrial fibrillation ablation. Horizontal lines indicate the means.

Figure 2 .

Number of patients with a hemoglobin fall 24 hours after the atrial fibrillation ablation of [?] $2 \mathrm{~g} / \mathrm{dL}$.

\section{Hosted file}

table 1 with a native check 20200601.xlsx available at https://authorea.com/users/335145/ articles/472415-a-smaller-post-procedural-hemoglobin-fall-in-patients-with-preexistinganemia-undergoing-atrial-fibrillation-ablation-with-a-single-skipped-dose-of-directoral-anticoagulants-another-anemia-paradox

\section{Hosted file}

table 2 with a native check 20200601.xlsx available at https://authorea.com/users/335145/ articles/472415-a-smaller-post-procedural-hemoglobin-fall-in-patients-with-preexistinganemia-undergoing-atrial-fibrillation-ablation-with-a-single-skipped-dose-of-directoral-anticoagulants-another-anemia-paradox

\section{Hosted file}

table 3 with a native check 20200601.xlsx available at https://authorea.com/users/335145/ articles/472415-a-smaller-post-procedural-hemoglobin-fall-in-patients-with-preexistinganemia-undergoing-atrial-fibrillation-ablation-with-a-single-skipped-dose-of-directoral-anticoagulants-another-anemia-paradox

\section{Hosted file}

table 4 with a native check 20200601.xlsx available at https://authorea.com/users/335145/ articles/472415-a-smaller-post-procedural-hemoglobin-fall-in-patients-with-preexistinganemia-undergoing-atrial-fibrillation-ablation-with-a-single-skipped-dose-of-directoral-anticoagulants-another-anemia-paradox

\section{Hosted file}

table 5 with a native check 20200601.xlsx available at https://authorea.com/users/335145/ articles/472415-a-smaller-post-procedural-hemoglobin-fall-in-patients-with-preexisting- 
anemia-undergoing-atrial-fibrillation-ablation-with-a-single-skipped-dose-of-directoral-anticoagulants-another-anemia-paradox
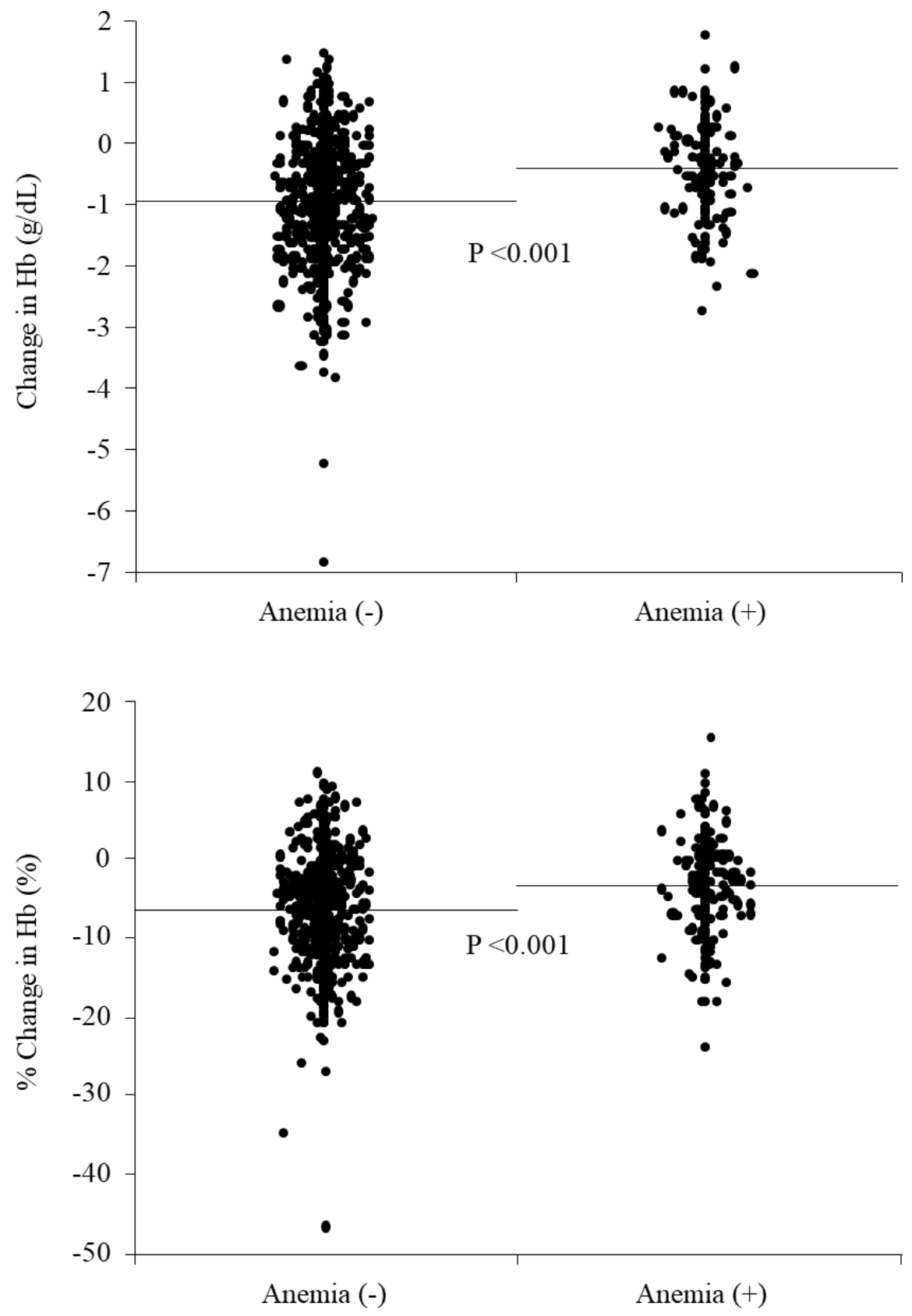


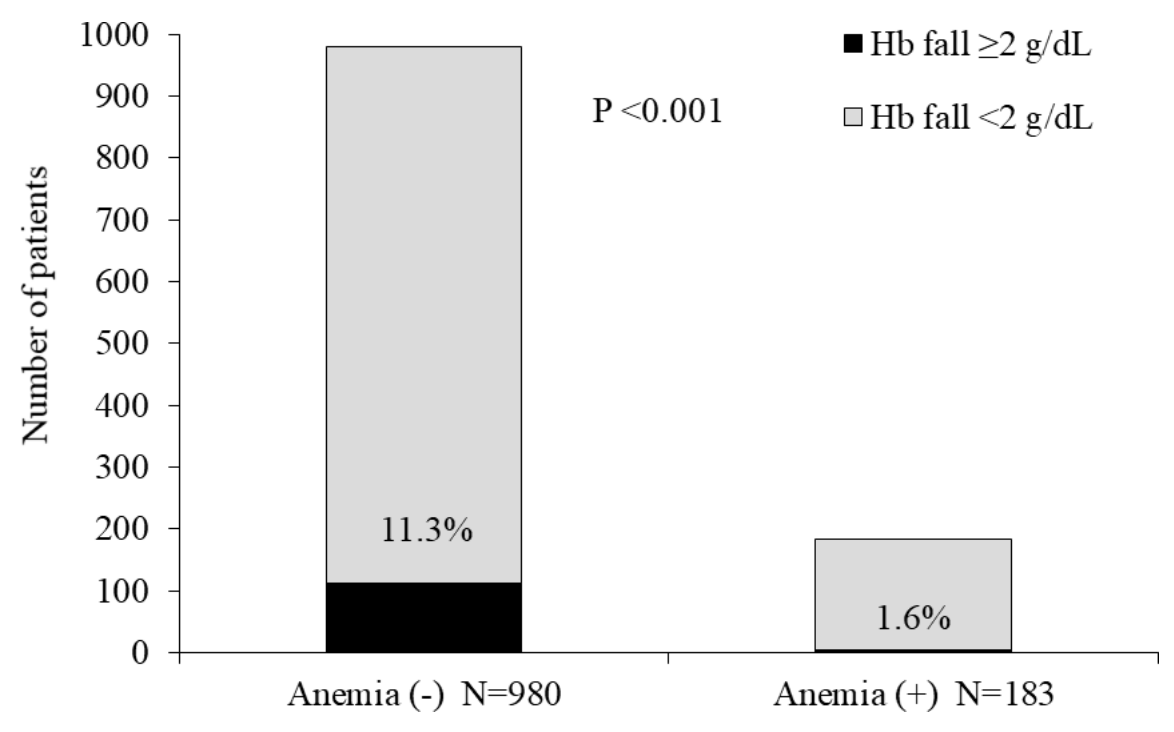

